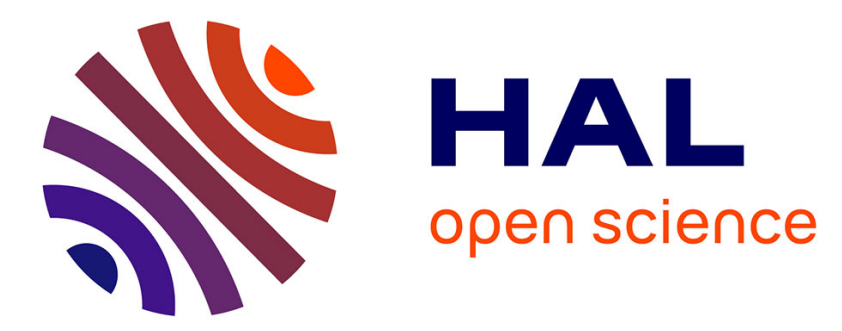

\title{
SAW wireless sensor and scale-based methods in fault diagnosis of rotating machinery
}

\author{
Angel Scipioni, Pascal Rischette, Agnès Santori
}

\section{To cite this version:}

Angel Scipioni, Pascal Rischette, Agnès Santori. SAW wireless sensor and scale-based methods in fault diagnosis of rotating machinery. International Symposium on Electromagnetic Fields in Mechatronics, Electrical and Electronic Engineering (ISEF), Aug 2019, Nancy, France. pp.1-2, 10.1109/ISEF45929.2019.9097086 . hal-03273732

\section{HAL Id: hal-03273732 \\ https://hal.science/hal-03273732}

Submitted on 29 Jun 2021

HAL is a multi-disciplinary open access archive for the deposit and dissemination of scientific research documents, whether they are published or not. The documents may come from teaching and research institutions in France or abroad, or from public or private research centers.
L'archive ouverte pluridisciplinaire HAL, est destinée au dépôt et à la diffusion de documents scientifiques de niveau recherche, publiés ou non, émanant des établissements d'enseignement et de recherche français ou étrangers, des laboratoires publics ou privés. 


\section{SAW wireless sensor and scale-based methods in fault diagnosis of rotating machinery}

\author{
Angel Scipioni \\ GREEN \\ Université de Lorraine \\ Vandœuvre-lès-Nancy, France \\ angel.scipioni@univ-lorraine.fr
}

\author{
Pascal Rischette \\ CREA \\ École de l'air \\ Salon-de-Provence, France \\ pascal.rischette@ecole-air.fr
}

\author{
Agnès Santori \\ CREA \\ École de l'air \\ Salon-de-Provence, France \\ agnes.santori@ecole-air.fr
}

\begin{abstract}
This article presents an essential step for identifying and locating faults encountered on rotating electrical machines. It is based on the use of a surface acoustic wave (SAW) vibration sensor. It ensures the capture of mechanical vibrations by a contactless and totally passive process. For the best determination of the resonance frequency, three processing methods are implemented: fast Fourier transform (FFT), discrete wavelet transform (DWT) and the empirical modal decomposition (EMD).

Index Terms-diagnosis, electrical machines, SAW, wireless, EMD, wavelets, FFT.
\end{abstract}

\section{INTRODUCTION}

The conditional maintenance strategy has been imposed in the industrial world. The obligation to control costs and therefore the need to perpetuate equipment have imposed vibratory diagnosis of rotating electrical machines (ISO 2372, 3495, 10816). The objective is therefore to identify and locate faults (lack of axles alignment, stator and rotor fields asymmetry, unbalance, bearing...). A first level analysis is not always sufficient to achieve this goal. A more in-depth approach (spectral or temporal) should therefore be considered.

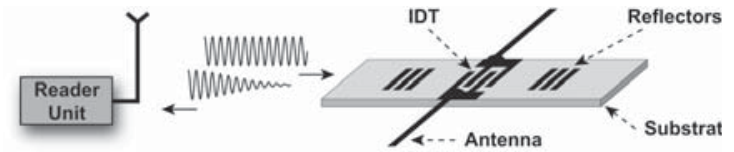

Fig. 1. SAW wireless sensor in one port resonator configuration.

\section{THEORETICAL BACKGROUND}

\section{A. Discrete Wavelet Transform (DWT)}

The discrete wavelet transform (DWT) is defined by the scaling mother function $\varphi$ linked to the wavelet mother function $\psi$ [4]. The signal is decomposed by two orthonormal bases defined as $\varphi_{j, n}(t)=2^{\frac{-j}{2}} \varphi\left(2^{-j} t-n\right)$ for approximations and $\psi_{j, n}(t)=2^{\frac{-j}{2}} \psi\left(2^{-j} t-n\right)$ for details, with $j$ : scaling factor, $n$ : translation parameter $\left((j, n) \in \mathbb{Z}^{2}\right)$. From a multiresolution analysis (MRA) point of view, the approximation filter $h$ and the detail filter $g$, low-pass and high-pass, respectively, are defined by $h[n]=\left\langle\varphi, \varphi_{-1, n}\right\rangle$ and $g[n]=\left\langle\psi, \varphi_{-1, n}\right\rangle$ where $g[n]=(-1)^{n} h[1-n]$. As it naturally separates the signal into approximations and details at different scales, the MRA is very well-suited to denoise a non-stationnary signal.

\section{B. Empirical Mode Decomposition (EMD)}

Unlike Fourier and wavelets, the EMD method analyzes a signal on an oscillating functions basis built algorithmically and progressively from the signal itself [5]. These functions are so-called IMF (Intrinsic Mode Function) and are built iteratively by subtracting the average envelope from the residual signal. This envelope is the mean of the upper and lower envelopes, itself based on cubic spline interpolation. Thus, the signal $s$ is written $s(t)=r+\sum_{k=1}^{N} \mathrm{IMF}_{k}$, with $r$ : the residue (3 extrema max), $\mathrm{IMF}_{k}$ : oscillating function at scale $k$ and $N \in \mathbb{N}^{*}$. Like DWT, the EMD method analyzes the signal into scales and is well-suited to denoising.

\section{METHODS FOR RESONANCE ESTIMATION IN ONE SHOT}

The proposed approach is based on the wireless insonification of a passive piezoelectric sensor (SAW). The mechanical vibration generated by the electric machine on which the SAW is fixed, distorts its piezoelectric support. This leads to changing the surface wave propagation between transmitter and reflector of the SAW. As a result, the SAW resonance frequency is altered. The latter contains the information we want to determine. The origin and location identification of the possible machine fault depends on the frequency estimation accuracy. The goal here is to estimate as precisely as possible the center frequency of the SAW resonator in one shot. We considered spectral and time approaches (possible because the coherent signal contains only one frequency). For the first one, we performed an FFT without prior processing since this one is robust to noise. For the time-based method, we denoised beforehand the signal with wavelets and EMD techniques [6], [7] and we applied a procedure of maxima detection. Finally, after computing the period between each maxima, we obtain the frequency by a simple average.

\section{RESUlTS AND DISCUSSION}

\section{A. Synthetical signals}

We generated SAW signals for 10 frequencies close to a usual intermediate frequency at $10.7 \mathrm{MHz}$ and for 21 signal-tonoise ratios (SNR) with $N=8192\left(2^{13}\right)$ samples, $F_{\mathrm{f}}=1.6 \mathrm{GHz}$ and $T_{0}=5.12 \mu$ s of duration. 
1) Measurement accuracy: Fig. 2 shows the relative average of gap between the estimated frequency $\widehat{F}_{\mathrm{r}}$ and the reference frequency $F_{\mathrm{r}}$ for each SNR value. FFT always gives the same result regardless of the SNR, which confirms its robustness against noise. These FFT values prove its inability to discriminate frequencies close to each other. For SNR = $-10 \mathrm{~dB}$, FFT is a better solution than wavelets and EMD. However, for any $\mathrm{SNR}>-10 \mathrm{~dB}$, the results are strongly reversed by a factor up to 10 . For $-2 \leqslant \mathrm{SNR} \leqslant-6 \mathrm{~dB}$, the results between wavelets and EMD are comparable, but for all the other SNR values, EMD provides best results.

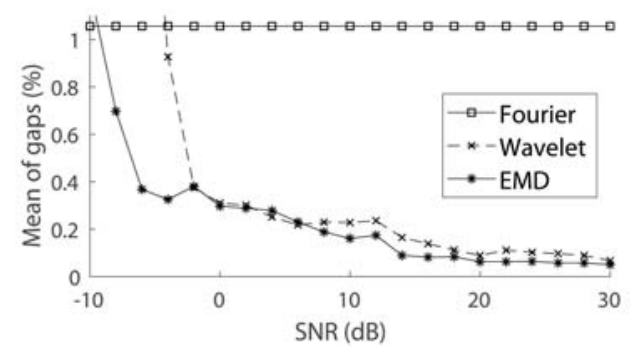

Fig. 2. Gap between estimated and reference frequencies versus SNR.

2) Measurement incertainty: The results are depicted in Fig 3. FFT always gives the same result regardless of the frequency. The reason is given by its spectral resolution which only depends on the time duration i.e. $\Delta F_{\mathrm{f}}=1 / T_{0}$. Thus, FFT uncertainty does not depend on the frequency or the number of samples. For the two time-based methods, the uncertainty $\Delta F_{\mathrm{t}}$ depends on the difference between two consecutive samples i.e. the sampling period $T_{s}$. The relation is given by $\Delta F_{\mathrm{t}}=F_{\mathrm{r}}-1 /\left(T_{\mathrm{s}}+T_{\mathrm{r}}\right)$, with $T_{\mathrm{r}}=1 / F_{\mathrm{r}}$ and $T_{\mathrm{s}}=1 / F_{\mathrm{s}}$. The results are here 3 times better than FFT.

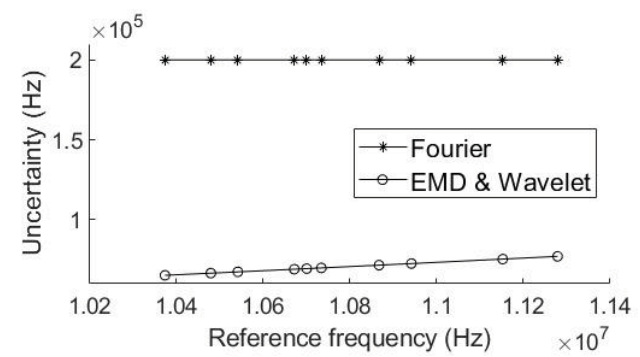

Fig. 3. Uncertainty of the estimated frequency versus the reference frequency.

\section{B. Experimental signals}

These signals are provided by the acquisition chain of the RF module depicted in Fig. 4. Table I and Fig. 5 show results for four signals and confirm the superiority of the time-based methods.

\section{Conclusion}

This work is an essential step of a defaults localization study in rotating electrical machines using a wireless SAW sensor for which the accuracy measurement of the central

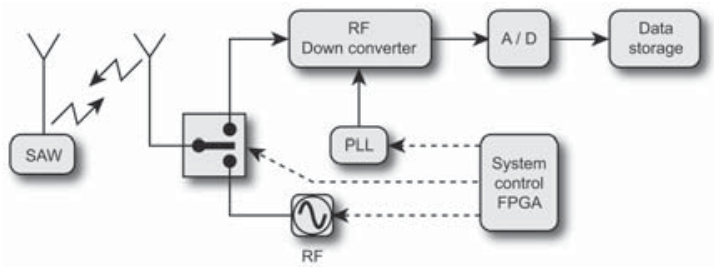

Fig. 4. Block diagram of the RF module used to collect the SAW signal.

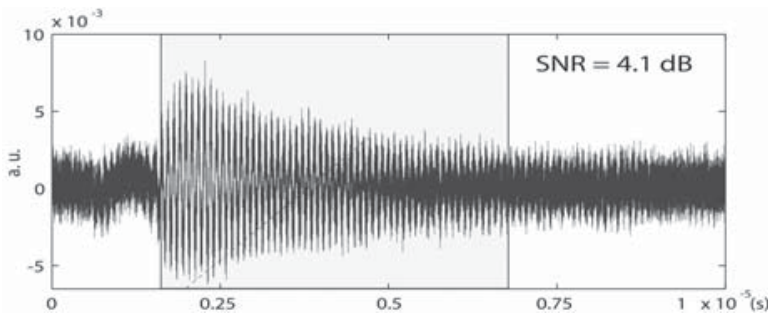

Fig. 5. Experimental SAW signal without filtering and lag used for the methods $\left(F_{\mathrm{S}}=20 \mathrm{GHz}, N=10^{16}\right.$ samples and $\left.T_{0}=5.24 \mu \mathrm{s}\right)$.

frequency is essential. The two time-based methods studied, and particularly the EMD, clearly give better results than the FFT in a factor from 1 up to 10 for the precision according to the SNR values and from 3 up to 12 for the uncertainty.

\section{REFERENCES}

[1] Y. Chen et al., "An intelligent chatter detection method based on EEMD and feature selection with multi-channel vibration signals," Measurement, vol. 127, pp. 356-365, October 2018.

[2] J. Filipiak et al., "Surface Acoustic Wave (SAW) Vibration Sensors," Sensors, vol. 11(12), pp. 11809-11832, December 2011.

[3] Y. Lei et al., "A review on empirical mode decomposition in fault diagnosis of rotating machinery," Mechanical Systems and Signal Processing, vol. 35(1-2), pp. 108-126, 2013.

[4] S. Mallat , "A theory for multiresolution signal decomposition: the wavelet representation," IEEE Trans. Pattern Anal. Mach. Intell., vol. 11(7), pp. 674-693, July 1989.

[5] N. E. Huang et al., "The empirical mode decomposition and the Hilbert spectrum for nonlinear and non-stationary time series analysis," Proc. Roy. Soc. London A, vol. 454. pp.903-995, March 1998.

[6] A. Antoniadis and J. Bigot, "Wavelet estimators in nonparametric regression: A comparative simulation study," J. Statist. Software, vol. 6, pp. 1-83, 2001.

[7] Y. Kopsinis and S. McLaughlin , "Development of EMD-based denoising methods inspired by wavelet thresholding," IEEE Trans. Signal Process., vol. 57(4), pp. 1351-1362, April 2009.

TABLE I

MEASUREMENT ON EXPERIMENTAL SIGNALS

\begin{tabular}{|c|c|c|}
\hline \multirow[b]{2}{*}{ Methods } & \multicolumn{2}{|c|}{ Estimated frequency $\widehat{F}_{\mathrm{r}}(\mathbf{M H z}), N=32768$} \\
\hline & Signal $1(S N R=8.3 \mathrm{~dB})$ & Signal $2(S N R=8.1 d B)$ \\
\hline Fourier & $10.53 \pm 152.6 \mathrm{kHz}(1.45 \%)$ & $10.53 \pm 152.6 \mathrm{kHz}(1.45 \%)$ \\
\hline Wavelets & $10.63 \pm 22.5 \mathrm{kHz}(0.21 \%)$ & $10.67 \pm 22.5 \mathrm{kHz}(0.21 \%)$ \\
\hline EMD & $10.64 \pm 22.5 \mathrm{kHz}(0.21 \%)$ & $10.66 \pm 22.5 \mathrm{kHz}(0.21 \%)$ \\
\hline & \multicolumn{2}{|c|}{$\begin{array}{c}\text { Estimated frequency } \widehat{F}_{\mathrm{r}}(\mathbf{M H z}), N=262144 \\
\text { Signal } \mathbf{3}(\boldsymbol{S N R}=4.1 \boldsymbol{d B})\end{array}$} \\
\hline Methods & \multicolumn{2}{|c|}{ Signal 3 $(S N R=4.1 d B)$} \\
\hline Fourier & \multicolumn{2}{|c|}{$10.98 \pm 76.3 \mathrm{kHz}(0.69 \%)$} \\
\hline Wavelets & \multicolumn{2}{|c|}{$11.057 \pm 6.1 \mathrm{kHz}(0.06 \%)$} \\
\hline EMD & \multicolumn{2}{|c|}{$11.069 \pm 6.1 \mathrm{kHz}(0.06 \%)$} \\
\hline
\end{tabular}

